\title{
An Album of Sports Photography as a Treatise on "The Philosophy Of Sports"
}

\author{
Anna Kossowska
}

Zamiejscowy Wydziat Wychowania Fizycznego i Sportu w Białej Podlaskiej, Poland

ABSTRACT

\begin{abstract}
The text discusses some attempts to present the most essential characteristics of sport with the use of selected photos showing human situations in different sports disciplines. Two albums are reviewed: the first one offering a more psychological aspect of sports processes, and the other focused more on the dramatic tension in sports and the challenges sport poses for the man. Composing such selected collections of photos is a significant method for presenting an image of sport as an organic cultural entity.

sport, album, photography
\end{abstract}

KEYWORDS

A peculiarity of contemporary sport is the fact that it is being diversified, different new disciplines are created, it becomes integrated with different spheres of culture, yet in iconography there is still an attempt to order sport and to grasp its uniformity, essence and system. An example of such putting things in order, which is not post-modernist, is constructing albums. They can and must gain recognition as an attempt to select "from the output of the coal mined", from the very life of sports events some pearls, some photos which are artistically meaningful. Photography is a higher level of reflection on sensual sport which is visible and can be observed. It is a small mirror on a segment of reality. Like any art, it animates the process of thinking, it inspires something new and, as Pontremoli writes, "carries senses which can be freely interpreted, which is not the same as a trivial confirmation of the world perceived" (Potremoli 2006, p.71). Photography is not merely a mechanical recording of different images of reality, copying the world, its naïve testimony, but also selecting a moment to be photographed, a creative activity and creation. The very sports reality also involves creative processes, creations of sports people who design sports events, and a photographer only grasps their achievements. In a sports episode, e.g. a header, a player creates a beautiful situation and the photographer can only capture it from the side or from below, and then he or she is creative, choosing the most dramatic and expressive view of scoring a goal. Photography records a moment, what is most essential in it, arrests the liquid, changeable reality in time, equipping that reality with a rank above its liquidity. It catches someone "red-handed", it is an attack, watching like a hunter. Like any art, photography not only "grasps" a present isolated moment (e.g. a high-jumper above a bar) asking two questions: what happened before and what is going to happen next?; but it also "arrests" the viewers and "catches" their eyes. 
On the Polish book market sports photography albums are rare. The exceptional works are Paweł Mystkowski's album The Beauty of Sport (Wyd. Artystyczne i Filmowe, Warszawa 1967) unfortunately, it did not have a sequel by the same auhor - and The Beauty and Bitterness of Sport, an album published by Świat Książki, crowning the exhibition The Olympic Games. Sport in Greek Art, organized at the National Museum in Warsaw from $15^{\text {th }}$ May to $4^{\text {th }}$ July 2004 . These are two concepts or panoramas of sport. The albums are not mutually complementary, they rather contradict and rule each other out, yet at some points they can be brought to a common denominator.

Two types of photographic imaging of sport. It may be worth starting by saying a few words about both parallels and contrasts which can be observed between the two albums. The first difference is that Mystkowski presents photos of anonymous sports people about whom we know nothing, he does not inform us in the captions who the people in the pictures are, which may suggest that it is not only sport that he is interested in. Maybe, while holding up a mirror to sports people, he wants to attract our attention to a man who is just like anyone else. Let him or her take a look in that mirror, offer the sports person's victories and defeats to the viewer and experience them in his own way. The other album refers to an accepted hierarchy and presents a personalized story, where the identity of the sports people is known, as well as their achievements. However, in both cases this is a chronicle of recorded sports events where, like in any chronicled activity, facts are noted, processes are reflected and some meaning is given to what is worth recording. The photos in the more recent album are not chronologically arranged. This is one of the artistic tricks - to deform time and space tricks characteristic of art.

Secondly, if we compare the albums on the ontic plane, then, characterising their structure it must be noticed that there is a serious difference between them. Unlike in Mystkowski's album, which has no author's thesis, though it is, as Bohdan Tomaszewski, one of the greatest sports commentators after the war, says in Foreword, "a loose collection, rather than an organised whole, with an introduction, unfolding and an epilogue with a conclusion" (Mystkowski 1967, p. 5), the album The Beauty and Bitterness of Sport intends to construct a novel with an introduction (the very graphic design of the cover is meaningful) and ending, where what matters is not only the order of the photos, their arrangement in pairs, but also the first and the last picture.

Thirdly, there is a border which makes the albums different in their individual approach to the criteria of the hierarchy of photos. Their authors look at them from two totally different perspectives. Mystkowski from the point of view of the same sports disciplines which group the pictures in complementary thematic series, but also from the point of view of successive stages of the development of a particular event (e.g. following sub-stages of a cycling tour). Sport is a process, it is not only a single, isolated, particular event (e.g. a javelin throw), but a series of events with a beginning, climax and ending. Mikołaj Burchard, the person responsible for the idea of the album The Beauty and Bitterness of Sport, sees the criterion of its hierarchisation in contrapuntal arrangements. This album is closer to the sport which obeys the rules of post-modernist culture and, consequently, the major part of photos presents not the process itself, but rather contrasts, either between experiences, different sports disciplines or between some fragments of one process. Such arrangements create a new value, i.e. they present something not really showing it, they encode a new value which provokes the viewer, to use Pontremoli's words, "to carry out unprecedented decoding" (Potremoli 2006, p. 69). Similarly, the captions accompanying Mystkowski's photos suggest the audience's interpretation, yet without imposing or subordinating anything, without excluding own interpretations. For example, captions such as "power", "skill", "acrobatics" or "speed" suggest that such qualities are elements of sports personality. The personality of a sports person is based on he or she being energetic, strong and skillful, and this is a definition of an image of a sports person, yet the 
captions, though revealing the author's intentions, may contain something more than a mere description.

Fourthly, the albums are different as far as colours are concerned: the first is black and white, whereas the other is colourful, pulsating with the whole spectrum of intensive colours. Mystkowski's album has a retrospective form and can seem to many people to be somewhat sentimental in nature: you can see there sports photos taken forty years ago which have not lost their magic or meaning and have not become outdated but, on the contrary, are still fresh, which is maybe because art never ages. Watching it, we become transferred to the black-and-white world of the Polish sport of the Sixties, more dramatic, as there are no halfway states, and more contrasting than in Burchard's colourful album, whose style is more realistic, cheerful and lyrical. In the world of Burchard's colourful photography album (the photos come from sports press from different countries of the world) there are more halfway states, the world has more shades and is more complex. There is no "either... or". On the contrary, black-and-white photography is a kind of artificial and metaphorical perception of the world, it deforms and impoverishes reality, depriving it of its colours. Colour photography reflects the world faithfully, it is passive and shows the charm and attractiveness of the colourful universe.

Fifthly, the contrasts between the two albums are also reflected by a complete lack of any advertisements in Mystkowski, whereas in the album from 2004, reflecting sport at the time of market functioning, it is visible that sport is being strongly advertised. Today sport has become a large industrial institution and a sports person is a means to make market mechanisms come true, and these can transcend sport and negate it. At present marketing is the essence of sports wisdom - and the matrix of truth is imposed by advertising. Companies buy sports people as carriers of advertisements. A sports person does not owe his or her success only to the rules of efficacy and perfectionism, but also to a marketing strategy - the point is to be liked by the spectators, to seduce and enchant them. This album also bears a stamp of commercial aestheticism and it does not free itself from the marketing sphere, as on its cover there are advertisements by firms sponsoring its publication. The cover, apart from the logos of sponsors, also contains symbols carrying a post-modernist message. A "clustering" trick has been used here, presenting two runners, as if showing one through the other - a contemporary one stylised to look ancient, following the canons of black-figure vase painting. This is something that makes the contemporary runner look archaic and unites him with the world of antique civilization. Composing such a cluster, the author may have intended to communicate his belief that it is impossible to separate sport from its antique origin. He shows the universal nature of sport, the fact that it existed in different epochs and cultures. And here is one more difference which makes the albums distinct. Mystkowski shows in his photos only Polish sports, he does not go back into the history of antique sport. Whereas in Burchard's album a reflection on sport looks deeply into its antique heritage. The authors of the more recent album are also trying to make a theoretical conceptualisation of sports in two articles: Wojciech Zabłocki's Sport Changeable or Unchangeable and Witold Dobrowolski's Sport and Olympic Games in Ancient Greece.

Closing the remarks concerning the albums, it is worth mentioning their titles, which also reflect their contrast. The first is more monothematic, its axiology is uniform, whereas the second is more dualistic and paradoxical. In both albums there are vertical photos, suggesting perfection, talking about going upwards, floating in the air, as well as rectangular, horizontal pictures with a tendency to make sport equal, where horizontal movement denotes staying close to the ground. Large-size photos are also a common feature, providing a more panoramic character, embracing the world of sport, carrying more meaning.

Yet the features mentioned above should not be misleading, since the most important point in assessing the albums is the extreme volume of their contents (ca. 150 pictures in Burchard's album and 95 in Mystkowski's) as well as an unprecedented variety of subject matter of the photos with the 
same, recurring, though processed variations of motives regarded as the so-called topos communis. It is worth taking a closer look at their themes, choosing a few direct examples.

General and individual characteristics of sports photography. The journey through the albums starts with the first photos. Comparing them, it could be stated that Mystkowski's album emphasises a particular feature of contemporary sport, which is its theatrical nature and the fact that it resembles a theatre play. This idea is expressed by a contemporary post-modernist writer, Wolfgang Welsch, who writes, "Sport and theatre take place in some definite space, separated from everyday reality. The stage in the theatre is equivalent to a pitch, a boxing ring or a racing circuit in sport. Sport and art, compared with life, are symbolic activities because of their structure" (Welsh 2003, p. 313). In the more recent album (in the first photo of the antique section, entitled The Harmony of Power and Beauty) what is stressed are the sacred elements of antique sport. These two presentations are so correct that they show, on the one hand, the obvious character of culture-centrism which is a characteristic feature of the contemporary epoch; in fact, culture has replaced religion. On the other hand, it is shown that religion used to be a central, supreme idea in the antique times when everything was subordinated to it. Today culture is a concept wider than religion, it is something independent. Since not every culture is religious. Culture, to quote Goethe, embraces man in his completeness.

The first photo of the contemporary section in Burchard's album, entitled Faster, Higher, Further presents a shadow of a female competitor, its size disproportionate in comparison with that of the pole held in her hand, which may suggest that it is not the muscles that count in the pole vault but the pole's elasticity and the pole vaulter's skilfulness in using it. The picture may be a metaphor for contemporary sport in which a competitor becomes only a machine to achieve results, to surpass barriers; the beauty, psyche, personality are not cherished as something more important than the achievement itself. But it is sport that should exist for the man rather than the man for sport. The photo represents the tendency of the album, which can be described as critical, towards the reality of sport as such. It provokes some anxiety resulting from the contemporary sport becoming too technical and the latest technique becoming the absolute which dominates the man. In such a situation a human being becomes only a supplement to a tool. He or she becomes an element of a machine. Another thought resulting from examining the photo is that during an activity such as pole-vaulting, the competitor stops being substantial, she becomes a temporary impulse of energy in the universe. The shadow is weightless. Gravitational forces stop working in sport, which becomes something volatile, weightless, not subjected to the laws of physics.

In both albums there are photos which, when arranged in pairs, either complementary or contrasting, not only reinforce each other's significance, but also undermine each other's unambiguity, gaining thus some new value. These are the photos whose sense depends on the context. They are an attempt to create some system, some definite view of sport, a concept which refers to something that is worth determining and recording. It is difficult to point to the best arrangement, yet if it was necessary it would be as follows.

A photographic series of three photos in Burchard's album, whose "protagonist" is archery. The pictures present in a definite order: the archer's equipment, a horse jumping over a fence and a female archer drawing the bowstring. They show a special moment, a surprising element in what is typical, arranged and predictable, giving a new meaning to the photographic series. This unusual, unpredictable and intriguing detail is an equestrian photo among archery pictures, suggesting that "an arrow" may be a metaphor for a larger group of phenomena, including a horse "flying like an arrow" over the fence. Placing such a picture in that set is a brilliant trick which we do not expect. It can be treated as a punctum, to use Roland Barthes' terminology (Barthes 1996, p. 47). This is a composition putting together a detail, an element and a whole. A series of similar archery photos, emphasizing the general character of the picture, was contrasted with a detail which ruins the former and explodes with 
something new, shocking, going beyond what organizes the whole, breaking the idea of a sequence, a series.

Another type of composition is used when two separate wholes are juxtaposed. Two rows confronted as a clash of generalities. This is seen in putting together the pictures whose protagonists are cyclists and speed skaters with their backs strained like an arch. The subject is a situation differing from an ordinary silhouette. This is an exceptional type of situation in reference to standard everyday situations. The differences between particular sports disciplines are not irreducible, they can be crossed within what is general about them. This grasps, in Barthes' terminology, a study of sports photography which is a presentation of a general situation, of what is general in a given phenomenon, e.g. dealing blows in a boxing match or football players kicking the ball (Barthes 1996, p. 46). This is a type of situation, not an intriguing detail but a type of phenomenon as a whole. This is what is general about different types of sport. Situations such as e.g. the shot-put or the javelin, where the arm is used to perform the throw, is something typical or general. Here, such generality prevails, a similarity of the same human attitudes and activities, showing the eidos of sport, the sporting nature in different areas of activities rather than a surprising, unique moment. Some photographic compositions are an attempt to combine in one whole something that is general, to unite the recurrent. They present in photographic series different disciplines of sport with the skilfulness of certain body parts, e.g. arms or legs, in the shot-put, boxing, high-jump, basketball or swimming, rather than an individual world of a single discipline. This is the generality which is inherent in the concurrence of the situation of spatial orientation, in grasping a similarity of the same position of the body in different sports disciplines e.g. in gymnastics and figure skating, where some analogies are found in the spatial position of the body, e.g. standing on one leg. There is no doubt that a large number of sports disciplines have a similar character resulting from the activity, e.g. a swimmer hitting the water and a tennis player hitting the ball. What we find here is the so called aesthetics of the hit (Symiotuk 1991, p. 2).

In such arrangements it is possible to find the sense of what Aristotle calls defining things according to their type and a specific, characteristic feature of an object (per genus et differentia specifica). This is an attempt to show something general and particular, something amazing in sport. Sport cannot be a routine or a disturbance which could add "flavour" to the whole, like an observed detail, e.g. blue fingernails or a bracelet belonging to a female runner, which is a specific feature added to a stereotype, not related to the nature of sport. To post-modernists, such ornateness as an ornament, accessories, willingness to look attractive is significant, they like such combinations from different spheres, such mixtures.

A situation which is particularly interesting is the punctum occurring in series, which is something exceptional in a given situation. For example, the open mouths of the tennis player and the swimmer, Otylia Jędrzejczak. The open mouth is not the eidos of sport, but rather something that breaks out of the typicality of the functional activity rule in a given discipline. Such particularities are a series of similar situations as a higher form of organising those images of reality.

Another interesting situation is juxtaposing two punctum, in a couple of photos presenting a marathon runner with his silhouette reflected in a shop window and two swimmers diving synchronically into the water. There are two puzzling moments here. In one case the special thing is that the competitor reflected in the shop window becomes double, which is also related to the effect. Reflections, glittering, delicate shadows, which are frequent motives in photos, introduce some complicated existence of things which have look-alikes, producing some extraordinary atmosphere around them. They make it impossible to close the picture of a sports person in a particular situation, in a specific definiteness, but they extend and reinforce the impression of movement and dynamics in sport itself. Pontremoli says, "Life is born out of reflections and shadows, out of all the glittering images which were given individual characteristics, out of the variety of the transitory universe" 
(Potremoli 2006, p. 97). In the second case the special thing is that the swimmers taking identical positions also become doubled. This is a juxtaposition of two punctum. We can discover the general character of that particularity. Particularities become grouped into something general. A detail has its type, it is exceptional. In different spheres different phenomena become exceptional. Puzzling phenomena, particularities can create a kind of untypical phenomena. These are especially complicated cases.

Sprint and marathon are two different types, two eidos of speed. Two forms of one phenomenon: higher and lower speed, which means contrasting quantities. You either reach the finish line quickly, or you run longer yet effectively and therefore win. Either accumulated effort, or an effort which is planned and lasts longer. In this juxtaposition, like nowhere else, it is possible to observe the quality gap between sprint and marathon, like between a fractal or a miniature and a macrophenomenon. This is exactly what is presented here: a contrast between elements in sport - a space in micro- and macro-scale. Sprint is a miniaturised space in reference to marathon. A picture corresponding to the above arrangement is the one showing only the legs of female runners in a 20kilometre walking-race. It shows the concurrence of the number of kilometres and legs. Each leg denotes one kilometre and presents the quality of that race, the length of the track. It shows the qualitative element of sport. An exceptionally meaningful example of photos presenting running is also an interesting situational photo of the blurred bodies of sportsmen who at a high speed produce a blurred picture of the world which becomes a trail of silhouettes. Sport lives in the world of velocity. We can see chaos rather than recognize durable elements. There is only a trail of passing images. Constructing the reality in sport has a generalising character. Numerous photos are blurred, which makes them dynamic, you can see that a sports person is running and not standing still.

Another set based on the contrast of "the lack" and "the surplus" is a picture showing a goalkeeper on an empty pitch, alone after failing to defend a goal, and a photo of cyclists riding in the main group, arm to arm. A surprising element in the first picture is some lack, a feeling of emptiness or a "hanging" absence. The pitch is untypical because, apart from the goalkeeper, there are no other people there. In the second photo a surprising element is the presence of a crowd of people. Those two extremities of the lack and the surplus produce an impression of uniqueness. The author emphasises here contrasts, diversity, opposition rather than similarities. The opposition is supposed to put stress on extreme human situations, such as becoming melted into an aggregate on the one hand and becoming isolated on the other, that is two extreme states of collectivity and individuality, where either a detail or a whole dominates. In sport you are either in a group as an element of a team, or the responsibility for the final result depends on you as an individual.

An extraordinarily meaningful example of contrasting juxtapositions is sets of photos showing table tennis players and curling competitors; a tennis player and a shot putter; a weight lifter and a gymnast performing on a bar - which, through a contrast of two types of aesthetics of lightness and heaviness, assume a meaning which is deeper than the current sports dimension. Such a contrast shows polar sides of the world, light and heavy elements which are meaningful in the universe (Bauman 2006, pp. 176-192). E.g. the spirit of lightness is cheerful while the body refuses to be obedient. Apart from photos with a characteristic motive of the aesthetics of lightness, e.g. a dancer on the ice rink lifting his partner, we also come across a contrasting picture with sports people in wheelchairs - the aesthetics of blockage.

Some photos expose the relativity of viewing a sportsman from different sides, e.g. viewing a skier from behind, which provokes an impulse in the viewer to jump themselves, as it is easier to identify yourself with the skier when you are behind than when he is jumping towards you. When we are watching sportsmen jumping towards us, photography reverses the natural order of things, it is not us who "enter" the picture with our eyes but the image which is heading in our direction. In one photo 
the rough, dark blue sea with a surfer gliding over the water like a fish seems to "flow" into the interior of our homes. We feel as if there was not enough air to breathe. In other pictures, where competitors are growing away in the space they consequently bring peace and calm to those who are watching them. An atmosphere of relief is created, but also one of discomfort or an impulse of "visual" pursuit to catch the departing sportsman (Symiotuk 1991, p.77). It is worth noting here that the aerial tradition of extreme sport goes back to a spectator sport which was performed for ages in acrobatic circus tricks, a technical skill developed to perfection. On the one hand technical perfection, and on the other hand artistic perfection including the beauty of movements and elegance. Ski jumping is closer to artistic spectator sport disciplines because they aim at inducing amazement and shock, due to the uniqueness of movements rather than ugliness.

The category of photos "watching" some body parts from the most unusual and surprising perspectives includes e.g. the pictures presenting "hands" suspended above the net, attacking and defending, for which a point of reference is the "feet" of synchronised swimmers directed with their front or back part to the pool. Both the hands and the feet are the protagonists, the actors of the event. Sport is not the sport of the whole body, but of its certain parts only which participate in different ways in achieving the final result. The organ of the result may be a single part or simultaneous cooperation of different body parts (e.g. in arm-and-leg disciplines). Another photo depicts a skier on an inrun and swimmers before the start of a race, exposing differences in the situation of their arms, a kind of deformation of the body leaning forwards and backwards, possibilities inherent in the drastic element of the body. Yet another picture exposes the bandaged foot of a gymnast, showing thus the problem of not only some special significance of passive body parts but also the fact that someone may have bad luck and that is impossible to overcome such bad luck. A situation like this puts an end to equal chances, this is like being handicapped by bad fortune. Sport includes elements of suffering, self-sacrifice, self-negation and paying some costs. Two other contrasting photos present wrestlers and an epeeist, where the element of amazement is the untypical shape of their bodies. Not only does sport lead to weird body figures, but these are also accompanied by a deformation of corporeality. This is also visible in the photo of a gymnast whose body, and especially arm, assumed a shape much different from the average functioning of a human body.

Each set is a finished-off entity which presents the complex nature of sport, like e.g. a photo by Robert Korzeniowski, the winner, contrasted with a photo of a knocked-out boxer. The contrast: either victory or defeat refers actually to the situation of alternative sport disciplines where someone either absolutely wins or absolutely loses (you cannot come second or third). There is nothing more dramatic than to be either on the podium or on the floor, where only victory counts and anything else is a defeat. Since although sport unites people, it also divides them into the better and the worse performers as far as pursuing perfection is concerned, and this is the tragedy of the people doing sport, one of the aspects of that rich phenomenon. Sport provides a hierarchy, following Aristotle, and divides people into the more energetic ones, having more entelechy and those who are more languid and have a plant, vegetative spirit and more matter. This juxtaposition undermines the unambiguity of both photos, and even to a higher extent expresses a will to introduce the sport in which the ability to experience both failures and successes is important, since a victory may become a beginning of a defeat and a defeat may turn into a beginning of a victory. A victory and a defeat, though being opposites which exclude each other, may arbitrarily change places. One moment may bring a victory and joy which can be soon followed by a disappointment. There is an internal dialogue here, communication between different phenomena from different areas of a given thematic field which can provoke an exchange of ideas. This is a kind of intellectualising sport, putting some thought, an idea into it. So the mess that we find at first sight in the album, a mixture of different sports disciplines and 
times, after careful observation leads us to discover a conceptualised view of sport, hidden in the arrangements of the photos.

Against this background, there is another arrangement, corresponding with the abovementioned, of two photos from Mystkowski's album, entitled "a great javelin thrower" and "a career with spikes", imposing a conclusion that it is the essence of sport that some people should be better while others should be worse. When we come to this place in the album its matter becomes dense due to presenting some emotional ambiguity resulting from a contrast of two different facial expressions. Two spiritual frames which are on the one hand an expression of fulfilment and satisfaction from the achievements, and on the other hand of some suffering felt under skin, impossible to control. Somewhere in the background there is anxiety, we subconsciously suspect the competitor's drama. "Spikes", which are of practical value, acquire a metaphorical meaning here and signify the sufferings of the sportsman, who has to strive for better and better results, which does not always end in a success. The contemporary sport is psychologised and a photo is a record of this psychological factor in sport.

An exceptionally photogenic picture is the one presenting a runner sitting on the track before the start. Our attention is attracted by his glasses (their colour aesthetics clashing rather than harmonising) in which a fragment of the track and stands are reflected. What we are trying to find in this picture is the emphasis put on a change of perception of the world. If you are a competitor the world consists of two elements only: the track and the spectators. You should not be interested in anything else but taking part in the race - only this matters. There is also a reflection of "the photography's optics", operating a camera, the situation of the photographer. To him, also the competitor is the most important, as well as the fact that he is starting. The photographer is "an eyeglass" which looks into the competitor's glasses.

An interesting photo is also the one showing a competitor with a big screen in the background, suggesting that sport is no longer an event that we watch directly, but is broadcast by machines as a picture only. The world on the screen is unreal, insignificant, whereas in the stadium it is important that you can see it.

There is a very colourful series of eight photos of sport fans, only one of whom has not had his face painted in national colours. This is a reversal of a certain order, and the unpainted face is the exception. A typical situation would be if he had his face made up, which is favoured by the atmosphere of excited support. This is a trick which lies in reversed proportions: the ordinary forms the exception. A general tendency is that sports fans like painting their faces, they want to become actors in an event. This photographic series also stresses the political significance of contemporary sport. If one represents a country, a cultural circle, then it is a kind of a war to win the prestige for nationalities. Another photo from the same series refers to aesthetic symbols rather than political ones and shows one more "freak" supporter who has red roses painted on his face. Our attention is seized by the contrast of the expressions on sports fans' faces, which enables us to see a symbolic course of events, from joy to sadness, where sport seems to be something warming up but also cooling down our passions. When the excitement is over, it brings peace and cool emotions. This is an intention inherent in the arrangement of the photos, and it goes beyond this arrangement. Among all arts, sport gives the viewer the largest area to become identified with what is being watched on the playground.

Setting a horserace against a Formula 1 race is meant to show updated means of movement it used to be a horse and today it is a machine. The photos emphasise the quality and historical differences. There are also photos (of fighting boxers and rugby players) presenting the aesthetics of muscles as a means of movement, as tools of sport. Some other photos record sport shifted into nature, 
in the forms of competition transferred to the animal world, where dog sledges become the main actors.

An interesting composition is a set of photos of hockey players and rowers, showing a problem of sport disciplines where tools held in the hand, such as sticks, are used and the way the players treats such tools: using them to push a boat or to push a puck. There are two situations of pushing here: pushing oneself and pushing a puck.

Several photos present how much spiritual and therapeutic strength today's sport can give to para-olympians. This is proved by the pictures showing blind people or competitors with amputated legs. Watching such pictures, the viewer, together with the protagonists, experiences not only the satisfaction of the victory, but also the feeling of reconciliation with life. We feel that they are able to look at their lives with love, rather than with bitterness, and that they know how to enjoy the beauty of the world. They are a testimony that even if something seems impossible at first, beyond man's capacity, and yet desired and treated as an aim, it can still be achieved. These photos and their stories emanate with sheer optimism. And a belief that the most serious threat does not come from outside, but lives inside us and poses the biggest challenge. We have to face it and fight. Sport is a criterion of truth, which makes it possible to state whether I am able to do something or not. Whether I am a pessimist, evading life and giving up competing, or an optimist taking up the fight. Sport is man's test, going beyond his capacity, transcending what has already been achieved. This reveals the eidos of sport. Since it is always about a victory or breaking a record, yet not at any cost, and always following the rules. These photographs are comforting, they lead to a conclusion which gives the viewer a cognitive satisfaction and a moral message. On the other hand, sportsmen with amputated limbs break the classical rules of sports aesthetics (the Greeks would not have organised this type of Olympic games) and their performance can arouse mixed feelings in some people. Still, this cannot negate the fact that their sports effort contains genuine values.

Our attention is also attracted by photos in which all types of substances, such as water or sand, on which competitions take place, become a metaphor for the whole imaginable space of movement, and at the same time its obstacle, threat, challenge and a partner for the sportsman's fight.

The photos presenting sportsmen in the background of a view reconstructing the façades of the architecture of Sapporo and Barcelona, reveal that sport functionally can also be a natural activity or an activity which is a fragment of civilisation. Sport depends on the context, it is either played in the natural environment or has civilisation as its background, some artificial space (special buildings, halls, stadiums). There is no such thing as pure sport. Sport exists only in relation to other areas of culture: architecture, nature, politics, economy, advertising or history.

Another set of photos based on a contrast is pictures presenting two situations which are decisive for achieving success in sport, such as scoring a goal and defence. These are the next lines completing the portrait of contemporary sport.

The albums arouse quite a lot of optimism, closing with a series of skiers' photos in Mystkowski and a dozen of pictures devoted to victory in Burchard. The essence of sport is to win without destroying the rival, it should be a pure, symbolic and noble victory. The loss is an addition, a shadow in sport, although it can also be meaningful, since a defeat can sometimes motivate people. "It teaches you distance and shapes your character", says the Polish pentathlete Dorota Idzi, winner of numerous medals in world and Europe championships. "Sport", she continues, "has taught me to win but also to lose" (Gawiński, Materiaty ...). Since this is not a defeat in its absolute sense and one does not lose their lives, yet it is a symbolic loss, which makes one try to continue winning. While winning, a clenched fist symbolises bravery and sport identified with military issues, whereas an open hand means the state of emotional relaxation, which is an element of the body language largely present in 
sport. Sports people use the language of gestures and this is why it is possible to take interesting pictures of them. In the photos with a motive of victory we can observe the feelings of involvement and the tension of spectators watching their competitor win. His states, his emotions are transferable, they are transferred from the actor onto the viewers. In sport spectators are arbiters, by all means, they support someone or are against someone else, they are someone's partisans. They are fans of one of the sides. Not always do they support the stronger one, sometimes they may identify themselves with the weaker competitor because they feel some sentiment towards him, they like him because he looks like their friend or a relative. Such subconscious identifications are irrational. The series of photos with the motive of victory provides a review of different abilities of reacting to the world and a versatility of emotions accompanying a victory in sport. This is a kind of psychological study of human reactions, a contribution to psychology.

The last photo in Mystkowski's album depicts beautiful mountainous scenery and a ski run, where the nature is the audience and a stage on which different sports processes take place. The perfect whiteness of snow, landscapes full of light, everything is beautiful like in a fairytale. This is the world of the cult of the mountains, in whose background the protagonist from Thomas Mann's The Magic Mountain appears, drawing his strength from the contact with nature. This is also the world of skiing as an ideology at the turn of the $19^{\text {th }} / 20^{\text {th }}$ centuries, a trend in culture claiming the cult of the mountains in which it was believed that the mountains have a peculiar ability to transform ordinary people in the street into noble ones. This is also the world of Zakopane, where artists used to come to experience a deep spiritual transformation when they were in the Tatra mountains. We can sense the remains of old rituals, gestures, activities performed by skiers, whose sense was seen first of all in the fact that skiing was a discipline for the elites, the intelligentsia, but it was also a sport of velocity, where the cult of speed was elitist in general and the speed itself was something noble, opposed to a worse, more ordinary existence. Such a photo does not close the album with a final situation, but it means that it could be finished. It is like an invitation: show me an alternative version of the ending; and also like a promise: I will show you other sides of sport and so will you, since this is only an initial letter of sport.

Also one of the key messages of the last large-size photo in the more recent album lies in pointing, while presenting Chinese dancers during a student inter-university sports championships in Beijing, to the "elitist" nature of this sport. Everywhere in Asia Chinese ballet is a highly-valued type of artistic rather than professional dance, it is regarded as a pseudo-religious phenomenon addressed at the elites and connected with high culture, rather than mass culture. While emphasising the acrobatic aspects of the dance where the beauty of movements counts, a return to a different concept of beauty in sport than the one related to efficiency and competitiveness is 176promoted, namely the one related to harmony. Certain disciplines of sport did not become dominated by marketing, mercantilisation, advertising; they preserved the relics of the old understanding of sport. Not all culture has become post-modernist.

These two ways of thinking about sport complete rather than exclude each other. They retain traces of elitism, or express sentimentalism to the old way of understanding sport as a factor creating elites. "Elitist sport", which the authors seem to be dreaming about, assumes in their albums forms of a project, an appeal to a certain model of sports eidos. They show the direction and they may be a call to treat sport more ambitiously than happens in pop culture, especially the plebeian (coarse, vulgar) sport addressed to the masses, through remembering the spirit of aristocratic sport, such as e.g. fencing, which has always been elitist. It used to be the sport of the ruling class (common people were not allowed to carry arms), and today it is not a popular sport, either. It is worth noting in this context that football was a plebeian sport at first and it was made more noble later, taking codified forms. Today it is a sport plebeian in its genesis, but its form has become culturised and civilised. Similarly, boxing, 
like football, was a plebeian sport discipline in its genesis, and took on somewhat more civilised forms later (referees do not accept unfair punches), yet its barbaric elements are still very powerful. It contains more aggressiveness than football because less aggressiveness is needed to kick a ball than to punch someone in the face.

However, the points listed above should not be misleading, as one of the significant motives closing the "considerations" of the more recent album is to present sport as being visionarily directed towards the future, defining itself through its tasks and duties which are still with us and awaiting us because of the Olympic Games in Beijing, which will become the axis of the Euro-Asian world next year. When we look at this photo somewhere in the background there is a question about cultural diversification of the model of sport in Europe and Asia. Sport is present everywhere in the world, becomes a global problem, but e.g. Chinese artistic dance is a certain peculiarity of Asia. Generally, in Asia there is less professional sport, competitiveness is characteristic of Europe. This difference is especially visible in archery. In Asia, this is an art of concentrating energy, it tends to identify the subject with the object, becoming united with the object in the act of shooting a bow, whereas in Europe it aims at the effect of the subject dominating over the situation and going beyond the limits of effectiveness. Asia is not disposed towards rivalry, the Asian people avoid brutality and do not talk about some blind, unreasonable necessity of nature, but they see in it the cosmic harmony and try to achieve not only harmony with nature, but also their own internal harmony and harmony with other people, claiming the primacy of contemplative activities. On the other hand, the Europeans prefer functional activity and sport expresses man's activeness in the most complete way.

The contemporary sports press is full of frequently excellent photographs which come and go and leave no trace in their mass. It would be worth selecting once in a while the most exquisite works of this type and publishing them in new albums with perhaps new methods of "philosophical" collecting them in one place. However, nothing can replace the joy of opening a well-designed album.

\section{REFERENCES}

Barthes, R. (1996). Światto obrazu. Uwagi o fotografii /The Light of the Image. Some remarks on Photography/. transl. J. Trznadel, Warszawa, p. 47.

Bauman, Z. (2006). Od ciężkiej do lekkiej nowoczesności; Kuszaca lekkość bytu /From Heavy to Light Modernity; Enticing Lightness of Being/. In Ptynna nowoczesność /Fluid Modernity/. Transl. T. Kunz, , Kraków: Wydawnictwo Literackie, pp. 176-192.

Gawiński, T. Materiaty z Polskiego Portalu Olimpijskiego/Materials from the Polish Olympic Web Portal/.

Mystkowski, P.(1967). Piękno sportu /The Beauty of Sport/, foreword by B. Tomaszewski, Warszawa: Wyd. Artystyczne i Filmowe, p. 5.

Pontremoli, E. (2006). Nadmiar widzialnego /An Excess of the Visible/, transl. M.L. Kalinowski. Gdańsk: słowo/obraz terytoria.

Symotiuk, S. (1991). Casus Dyskobola. Kulturowe aspekty filozofii rzutu. /The Case of the Discus Thrower. Cultural Faces of the Philosophy of Throwing/. Przeglad Humanistyczny, no 2.

Welsch, W. (2003). Sport - przez pryzmat estetyki, a nawet widziany jako sztuka? /Sport - Seen from the Angle of Aesthetics and even Seen as a Form of Art?\%. In Media - eros - przemoc. Sport w czasach popkultury, (Ed.) A. Gwóźdź, Kraków, p. 313. 